\title{
Culture of missing girls: Anthropological insight in culture, medical technologies and medicine
}

\author{
Ravinder Singh $^{1 *}$, Vibha Sharma ${ }^{2}$, Sarbjeet Khurana ${ }^{3}$, Upmesh K.Talwar ${ }^{4}$ \\ ${ }^{1}$ Associate Professor \& Head, Department of Medical Anthropology, Room No 120, Academic Block, Institute of Human Behavior and \\ Allied Sciences(IHBAS) Hospital, GNCT Delhi, Dilshad Garden, Delhi \\ ${ }^{2}$ Associate Professor, Department of Clinical Psychology, Academic Block, Institute of Human Behavior And Allied Sciences(IHBAS) \\ Hospital, GNCT Delhi, Dilshad Garden, Delhi \\ ${ }^{3}$ Associate Professor \& Head, Department of Epidemiology, Academic Block, Institute of Human Behavior And Allied Sciences(IHBAS) \\ Hospital, GNCT Delhi, Dilshad Garden, Delhi \\ ${ }^{4}$ Assistant Professor \& Head, Department of Social Work, Model College of Education, Mahatama Joytiba Phule(MJP) Rohelkhand \\ University, Bareilly, UP \\ *Corresponding author E-mail: medicalanthropology.ihbas@gmail.com
}

\begin{abstract}
This paper illuminates cultural domains wherein we try to locate the causes of missing girls in Punjab. The prevailing cultural constructions of the social structures wherein girls are born in outnumber as compared to boys, but due to latter they continue to diminish since ancient times. It captures on one side the state historical efforts to check it by social legislations during the eighteenth, nineteenth centuries and during the pre \& post independent periods. Further on other it links to the efforts of the State government to illuminate how advancement in medical technologies and medicines had been grossly mis/used to determine sex of unborn child and concludes that how these technologies have emerged as the integral parts of culture of Missing girls.
\end{abstract}

Keywords: Missing Girls, Culture, Medical Technology and Demographic Variable.

\section{Introduction}

Anthropologists have widely reported the phenomenon of infanticide. It has been practiced across the worldwide cultures of the people at every level of cultural complexity, from hunters and gatherers to high civilization, including our own ancestors. There are historical evidences about the parents who used to murder their children under the stressful situations. In nineteenth century practices of infanticide was common in England, Greece and Persian Empire. There were diverse reasons for this inhuman destruction. Two reasons, most statistically important, were seems to be poverty and population control. Since prehistoric times, the supply of food has been a constant check on human population growth. One way to control the lethal effects of starvation was to restrict the number of children allowed to survive to adulthood. It was Darwin who believed that infanticide, "especially of female infants," was the most important restraint on the proliferation of early man argued Williamson (1998). She further elaborates on the evidences from cultural beliefs, customs or rituals prevalent in Arabia, in Judaism and Christianity, in India and China. Infanticide still continues in modern times in colonial and mentioned with a statistical analysis of infanticide in modern America, as well as in other parts of the worlds. Female infanticide has been continues for centuries as a prominent and socially acceptable event in India and China despite the religious prohibitions against infanticide by the major religions. The extent of the problem is measured in frightening proportions: "at least 60 million females in Asia are missing and feared dead, victims of nothing more than their sex. Worldwide, research suggests, the number of missing females may top 100 million." The data estimates indicate that 30.5 million females are "missing" from China, 22.8 million in India, 3.1 million in Pakistan, 1.6 million in Bangladesh, 1.7 million in West Asia, 600,000 in Egypt, and 200,000 in Nepal (ibid). Today the killing of females has presented in its ugliest shape as female feticide in our country (Mallick, 2004; Anand, 2004; Krishna and Vani, 2004). Unfavorable sex ratios for females have largely been the result of a preference for a son by Indian families (Rastogi and Kumari, 1992; Basu, 1989) especially in Northwest India (Miller, 1989).

Anthropologists have described the north-south divide where southern Indian society was considered more female-friendly. The discriminatory attitudes in northern India are manifested by practices such as female infanticide, neglect in terms of healthcare and food allocation and, more recently, as female feticide (Miller, 1985). According to the 2001 Census the worst child sex ratios have been noted in Punjab (798), Haryana (819), Delhi (868), Gujarat (883), Himachal Pradesh (896), Uttaranchal (908) and Rajasthan (909) (IIPS,2005). This belt of states has been reported to have widespread advertisements for sex determination tests and for induced abortion including the rural areas. The facilities for performing them are also readily available. Another cause for worry noted by this study is that even the southern states have skewed ratios at birth and the practice of sex determination is probably flourishing nationwide (IIPS, 2005).

In this essay we have made an attempt to develop an anthropology of reproductive processes: a trajectory from infanticide to foeticide, influences of pharmaceutical formulation affecting 
reproductively effective years: pill, injection, etc. and other use of pharmaceutical material for not to conceive; intra uterine devices (IUD) users etc. in order to probe the operating forces which leads for "planned or unplanned reproductive waste". We have used National Health and Family Survey (NHFS-3) (IIPS, 2005) and District Level Health Survey-Reproductive and Child Health (DLHS-RCH,2002-04) data for the interpretation the various aspects of demographic variables- age at marriage, fertility level, teenage pregnancy, birth interval, the fertility preferences etc. on one hand and Maternal and child health- maternal and child mortality rate; family planning, newer medical technologies and medicine and efforts of Punjab state Legislation on other hand to construct the prevailing images of the Girls child being maintained in our culture and inheritance of these images from women to their girl child-(un)born. Through this analysis we developed an insight, for causes and possible solution of these missing or lost girls in Punjab, which we feel, lies in the cultural ecology of these districts.

\section{Cultural anthropology of birth and death}

Anthropologists have documented the cultural aspects of the birth in the cross cultural studies (Browner and Sargent 1996; Davis-Floyd and Dumit, 1997). A historical transformation in theories of birth has been described in an ethnography related to the relationship between modernity and childbirth in Tamil Nadu, India (Van Hollen 1994). She described in her work the anthropological approaches to study reproduction focusing on reproductive practices and beliefs as reflected in social and cultural system (Van Hollen, 2003). Anthropologists can further enhance their gaze to look the reproduction as the key site where people (re)conceptualize and (re)organize the world in which they live. Similarly, anthropological studies documented different aspects of production of mothers by means of technocratic birth practices and the gender division of body and labour function; mothers of disabled children (Parson,2004; Landsman 1998), infertile women(Becker,2000; Inhorn and Van Balen, 2002; Kahn,2000) have contributed greatly to the phenomenon of birth.

The death, as anthropologists view, when it came in earliest moments of life such aspects have been examined to redesign the death: reproduction imaging technologies and parental genetic testing (Rapp 1999); social response to pregnancy loss, mainly miscarriage (Cecil, 1996; Layne, 2003); fetal surveillance to intervene in pregnancy (Hartouni, 1997), differential rates of infant mortality rates by gender, race, nationality(Greenhalghs,2003;Miller 2001). Bastian (2001) expressed those differential rates of infant mortality rates by gender, race, nationality social order (Bastian, 2001). Feminist anthropologists recently have begun to focus on dead embryos and fetuses. These have gained the attention of public consciousness hence need more systematic explanation (Morgan, 2002). Anthropologically produced ethnographies of pregnancy loss reveal that how the miscarriages as silenced or miscarried embryos became socially invisible. Anthropologists have critically examined the subjectivity and potency of Japanese practices of fetal loss and abortion (Csordas, 1996; Hardacre,1997;Oaks,1994; Picone,1998). Such qualitative studies need to be done in our own community, particularly in Punjab with low sex ratio districts, required to be produced for the qualitative explanation of pregnancy loss- why sex ratio is declining in Punjab districts it must be explored qualitatively from the anthropological perspective. Historically it is established that the practices of female infanticide in our country had deep roots in the socio-cultural fabric of the society. Following description reveals the female infanticide had been rooted in our social fabric.

\subsection{Culture of missing girls: female infanticide in Brit- ish India}

In 1789 the British discovered female infanticide in India. In both, north and west India, the British knew that female infanticide was practiced by the upper caste, landowning Hindus who wielded power at the local level. This being so, they wanted to play it safe keeping in view the safety of their Indian possessions by resorting to legitimate action against female infanticide with the consent of the groups who practiced it. And what action could be more legitimate than reminding the caste which resorted to the practice about the injunctions against infanticide in their own shastra and puran?

British Residents reported that Rajas in Benares and Rajkumar rajputs in Jaunpur district destroyed their female children. It was brought to the notice then Governor General of British India. Similarly in 1800 western Indians in Surat, the Jadeja rajputs of peninsular Gujarat in Kathiawad, and Kutch killed their female children. British discovered female infanticide in various parts of north and west India was very common. According to reports of British officials, the castes resorted to the practice in the 19th century were: rajputs, jats, ahirs, gujars, khutris and moyal Brahmins in north whereas the rajputs of peninsular Gujarat, lewa patidars and kanbis of mainland Gujarat practiced female infanticide in west India. These castes were dominant at the local level in different parts of north and west India (Vishwanath, 1998).

Commonly prevalent female infanticide and elaborate correspondence and reports in that time forced British government to enact Female Infanticide Act in 1870. These reports mentioned about the methods and strategies adopted by the British rulers to stop female infanticide. There is information on the social institutions related to female infanticide then common in our society. The British colonial administration did not have a uniform policy for suppressing infanticide in the late 18th and 19th century. Since the practice was found to be prevalent among some landowing Hindu castes, the British first employed the injunction against female infanticide in Hindu sacred literature to suppress the practice. Later, when they found that this ways was not helping in the suppression of the practice, they resorted to coercion to stop female infanticide. It is noteworthy that the British administrators used sacred texts to stop female infanticide in the early years of their rule, that is, late 18th and early 19th century. By the 1830s coercion and persuasion of a different kind not based on shastra or puran was adopted to put down female infanticide. Though local officials had given up using Hindu religious texts to check female infanticide well before the mid-19th century, the law courts in the Bombay presidency even in 1852, based their decisions on regulation passed by government which excluded caste questions from judicial review and provided that Hindus and Muslims should be governed by their own 'laws and usage's' as laid down in the shastras for Hindus and the Koran for Muslims.

In the Punjab region of north India, the bedi khatris practiced female infanticide extensively in the 19th century. The bedis were an influential caste of Sikh khatris who claimed high rank among Sikh khatris and also claimed to be descendants of the founder of the Sikh faith, Guru Nanak, Major Lake reported to the Punjab Board of Administration in 1851 that "it is an undoubted fact that there are a 1,000 families of bedis who, for the last 400 years have destroyed all their female offspring". The bedis received girls in marriage from khatri families of lower status but they refused to marry their daughters to boys from lower status families and instead resorted to female infanticide (ibid).

\section{Anthropology of demographic variables}

Demographic variables in Punjab are briefly described: age at marriage, fertility level, teenage pregnancy, birth interval and the 
fertility preferences and examined as the reflection of the changing social structure that has affected the reproduction pattern of the people in the State. The variables like family planning, knowledge and use of the contraceptive, maternal care and infant mortality rate which are exclusively used here in order to reflect prevailing situations (NFHS-3) (IIPS, 2005).

i. Age at first marriage: The median age is 19.8 years at first marriage among women age 20-49 yrs whereas it is 23.5 years among men age 25-49 years. It is interesting to note that average men get married about four years later than women, about $1 / 5$ th of women age 20-24 years got married before the 18 years and 27 percent of men age 25-29 years got married before 21 years to their legal minimum age.

ii. Fertility levels: Women in Punjab have an average of 2.0 children in her lifetime at current fertility levels. Fertility is lower than replacement (1.9) in the urban areas and it is in the rural areas at replacement level (2.1). Among births in the three years preceding the survey, only 12 percent were of birth order four or higher. Fertility has declined by almost one child since the time of NFHS-1. However, most of this decline occurred between NFHS-1 and NFHS-2. Between NFHS-2 and NFHS-3, fertility declined only marginally by 0.2 children. Fertility is at or below replacement level in Pun$\mathrm{jab}$ as a whole as well as in its urban and rural areas (NFHS3).

iii. Teenage pregnancy: Among young women aged 15-19, 6 percent have already begun childbearing much lower than the national average $(16 \%)$. One percent of women age 15 have started childbearing, but among women aged 19, almost onefifth $(18 \%)$ are already mothers or are pregnant. The percentage of young women who have begun childbearing decline sharply with education, from 18 percent among those with no education to 2 percent among those with 10 or more years of education.

iv. Birth intervals: The median interval between births in Punjab is 30 months, about the same as the national average of 31 months. Eighteen percent of births take place within 18 months of the last birth, and 35 percent occur within 24 months. Almost two-thirds of births occur within three years. Research shows that waiting at least three years between children reduces the risk of infant mortality.

v. Fertility preferences: Seventy-nine percent of currently married women and 76 percent of currently married men in Punjab want no more children or one of the partners is already sterilized. Among those who do want another child, about one-third of women and half of men would like to wait at least two years. Eighty-one percent of women and men in Punjab consider the ideal family size to be two children or less.

There is wide preference for son in Punjab. Eighteen percent of women and 13 percent of men want more sons than daughters, but only 2 percent of women and men want more daughters than sons. However, most men and women would like to have at least one son and most would like to have at least one daughter. Among currently married women with two children, 97 percent of women with two sons and 95 percent with one son want no more children, compared with 43 percent of women with two daughters only. Notably, however, the proportion of women with two daughters and no sons who want no more children has almost doubled since NFHS-1. The proportion of women with two children who want no more children has increased considerably in the period between NFHS-1 and NFHS-3, although most of this increase took place between NFHS-1 and NFHS-2. In Punjab, unplanned pregnancies are relatively common. If all women in Punjab were to have only the number of children they wanted, the total fertility rate would be 1.5 instead of 2.0 .

These demographic indicators: age at marriage, fertility level, teenage pregnancy, birth interval and the fertility preferences present the alarming picture as far as the sex ratio decline concerns. The drastic decline in fertility in the entire Punjab must be explored systematically. Anthropologically the constraints in fertility have been analyzed. It is observed that none of the variation in total fertility from one population to another population appears to be explained by variation in age at menopause, the level of intrauterine mortality, or the length of gestation. Similarly the variation age at menarche can explain a little about the variation in fertility which is also affected by various sexually transmitted diseases (STDs) which may dramatically reduce the fertility of the community (Trussell, 1979). Variation in the fertility can be explained by five intermediate fertility variables: (i). Duration and intensity of breast feeding (and period of postpartum abstinences), (ii).Proportion of married women (sexually active), which may function primarily as a proxy for the frequency of the coitus (Trussell, 1979). (iii). Fecund ability- as the probability of conception with in frame of time (Wood and Maxine, 1988). (iv). Effectiveness and use rate of Contraception and (v) Incidence of induced abortion (Handwerker, 1990). The role of education in improving sex ratios is dubious.

\section{Family planning}

\subsection{Knowledge of family planning methods}

People are well aware about the knowledge of contraception in Punjab. Most of the women are aware about female sterilization and it is the most widely known method among all women, while condom is the most widely known method among all men. The government family planning programme promotes three temporary methods: the pill, IUD, and condoms. Of these three methods, currently married women are most likely to know about the pill $(92 \%)$ and currently married men are most likely to know about condoms $(99 \%)$.

\subsection{Contraceptive use}

The contraceptive prevalence rate among currently married women is 63 percent; Contraceptive use is slightly higher in rural areas $(64 \%)$ than in urban areas $(62 \%)$. Contraceptive prevalence increases with age to 75 percent among women age 30-39 and then declines. In keeping with son preferences, women in Punjab are more likely to use contraception if they already have a son. For example, 77percent of women with two sons but no daughters use a method of family planning, compared with only 45 percent of women with two daughters but no sons. In Punjab contraceptive use is particularly low among Muslim women $(49 \%)$ and women who have less than five years of education $(57 \%)$. The only women with a much higher than average contraceptive prevalence rate are women who are employed for cash (72\%).The most commonly used spacing method by currently married women in Punjab are condoms $(16 \%)$, followed by the IUD $(6 \%)$. In general, better-educated and wealthier women and women from urban areas are more likely to use modern spacing methods. Female sterilization is more common among less educated and disadvantaged women. Contraceptive prevalence has decreased from 67 percent in NFHS-2 to 63 percent in NFHS-3; however, the use of condoms and female sterilization has increased during the same period. The decline is sharpest in traditional method use, but the use of male sterilization, the pill, and the IUD has also declined or remained unchanged in the years between NFHS-2 and NFHS-3. Female sterilization, which accounted for 44 percent of contraceptive use in NFHS-2, now accounts for 49 percent of contraceptive use. Contraceptive use in Punjab is higher than the national average, but lower than in $\mathrm{Hi}-$ machal Pradesh (NFHS-3).

IUD and Pills Users: Fifty-seven percent of currently married men report using contraception the last time they had sex. Ninetytwo percent of sterilized women had the operation in a government facility, most often in a government or municipal hospital, whereas more than half of IUD users had their IUD insertion in the private medical sector. Almost two-thirds of pill users got 
their most recent supply from the private medical sector, which is also the most common source for condoms. However, 8 percent of pill users and 18 percent of condom users did not mention any source but said that they obtained their supply from their husband. According to women's reports, among users for whom the brand is known 66 percent of pill users and 51 percent of condom users use social marketing brands. According to the men's reports, 44 percent of condom users for whom the brand is known use social marketing brands. The one-year discontinuation of contraceptive methods is lower in Punjab (20\%) than in the country as a whole $(27 \%)$. One-fourth of all users of spacing methods discontinued use within the first year after they adopted the method, compared with the national average of 39 percent. Fifteen percent of IUD users and 26 percent of condoms users discontinued use within the first years of use.

Women who are aware about kinds of contraceptive methods and their side effects can make better choices about which method to use. Thirty-seven percent of women using a modern contraceptive method were told by a health or family worker about the side effects of their method, 29 percent were told what to do if side effects occurred and 32 percent were told about other methods they could use. Most men in Punjab (84\%) reject the idea that contraception is women's business and a man should not have to worry about it and reject the idea that women using contraception may become promiscuous (88\%). However, 48 percent of men incorrectly believe that women who are breastfeeding cannot become pregnant and only 57 percent of men know that a condom, if used correctly, protects against pregnancy most of the time.

Married women who either want to space their next birth or stop childbearing entirely but are not using contraception. Accordingly 7 percent of currently married women in Punjab have an unmet need for family planning, which came down from 13 percent in the first Survey of NFHS. Presently 90 percent of the demand for family planning is being met in Punjab it is very much higher than the national average of 82 percent.

\section{Infant and child mortality}

Infant mortality in NFHS- 3 is estimated at 42 deaths before the age of one year per 1,000 live births, down from the NFHS-2 estimate of 57 . The under-five mortality rate for Punjab is 52 deaths per 1,000 live births, down from the NFHS-2 estimate of 72. The NFHS-3 rates imply that, despite declining mortality, more than 1 in 24 children in Punjab still die within the first year of life, and 1 in 19 die before reaching age five.

Infant mortality does not vary greatly between the urban and rural areas of Punjab. Children whose mothers have no education are more than one and half times as likely to die before their first birthday as children whose mothers have completed at least 10 years of school. After the first month of life and before they are five years old, girls in Punjab face a much higher mortality risk than boys. The child mortality rate by sex shows that the gender differential in mortality is particularly high for children above the age of one year. The child mortality rate for girls is 16 deaths per 1,000 children age 12-59 months, compared with only 6 for boys. Children born to mothers younger than 20 years or over 40 years of age are more likely to die in infancy than children born to mothers in the prime childbearing age. Infant mortality is 60 per 1,000 for teenage mothers, compared with 40 for mothers age 2029. Having children too close together is especially risky. Children born less than two years after a previous birth are more likely to die than children whose mothers waited 2-3 years between the births.

\subsection{Perintal mortality}

Perinatal mortality, includes stillbirths and very early infant deaths (in the first week of life), is estimated at 33 deaths per 1,000 pregnancies that lasted 7 months or more. Perinatal mor- tality is somewhat higher in rural than in urban areas. Pregnancy intervals also have a strong effect on perinatal mortality. The perinatal mortality rate is much higher $(44$ per 1,000$)$ for pregnancies that take place less than 15 months after the previous birth than for pregnancies that take place at least 39 months after the previous birth $(28$ per 1,000$)$.

\section{Maternal health}

i. Antenatal care: It is observed 83 percent of the women percent received antenatal care from a health professional, 56\% from a doctor, 26\% from an ANM/Lady Health Visitor/nurse/midwife, and 1\% from other health personnel. Almost all women with 10 or more years of education and women in the highest wealth quintile received antenatal care. Notably however, 38 percent of women belonging to the second wealth quintile, 22 percent of women with no education and women belonging to the middle wealth quintile, and 21 percent of women having a fourth or higher order birth did not receive any antenatal care. Sixty percent of women received antenatal care during the first trimester of pregnancy, as is recommended. Another 20 percent had their first visit during the fourth or fifth month of pregnancy (data not shown in tables). Three-fourths of mothers had three or more antenatal care visits; urban women were more likely to have three or more visits than women in rural areas (IIPS, 2005).

The proportion of ever-married women with a birth in the three years before each survey who received any antenatal care for their last birth has increased by 16 percentage points between NFHS-2 and NFHS-3: from 75 percent to 91 percent. There has also been a considerable increase in the proportions of women with at least three antenatal care visits and women who had their first antenatal care visit in the first trimester of pregnancy (14-15 percentage points each) in the seven years between the surveys. However, even when women receive antenatal care, they do not always receive several of the services needed to monitor their pregnancy. Only 72-76 percent each of women who received antenatal care had their abdomen examined, urine tested, blood tested and blood pressure measured, and even fewer had their weight taken (60\%). Only 18-28 percent of women who received any antenatal care were told about pregnancy complications and 59 percent were told where to go if they experienced pregnancy complications. Among women having a live birth in the five years preceding the survey, mothers received iron and folic acid supplements (IFA) for 66 percent of births; however, they consumed IFA for the recommended 90 days or more for only 28 percent of births. More than four in five mothers received two or more doses of tetanus toxoid vaccine. Only 3 percent took an anthelminthic during pregnancy. An ultrasound test was performed during 45 percent of pregnancies, much higher than the national average of 24 percent. Two-thirds of pregnancies to women with 10 or more years of education and women belonging to the highest wealth quintile had an ultrasound test. Women with at least 10 years of education were almost three times as likely to have an ultrasound test as women with no education. Pregnant women having one or two children but no living son are more likely to have an ultrasound test.

ii. Delivery care: Almost half of the births in Punjab take place at home and half in a health facility. Among births in the five years preceding the survey, 65 percent of first births were institutional births, compared with only 27 percent of births that were of order 4 or higher. The proportion of births in health facilities increases sharply with the education and wealth status of the mother. About three out of four deliveries of mothers who have 10 or more years of education and who belong to the highest wealth quintile take place in a health facility. Institutional births are also more common among urban women, Sikh women, and women who received four or more antenatal care visits. Institutional 
births increase sharply with the wealth status of the Household. The percentage of institutional births among all births in the three years preceding each survey has increased steadily from 25 percent in NFHS- 1 and 38 percent in NFHS-2, to 53 percent in NFHS-3.

Home births are more common among women who received no antenatal check-ups, rural women, women with no education, scheduled caste women, older women, and women with more than three previous births. Women who gave birth at home were asked why they did not deliver in a health facility; by far the most common reason was that they simply felt it was not necessary $(70 \%)$, followed by the reason that an institutional delivery is too expensive $(28 \%$; data not shown in tables). In 84 percent of home births, a clean blade was used to cut the cord, as is recommended, and 87 percent of home births followed the recommendation that the baby be immediately wiped dry and then wrapped without being bathed first. Sixty-eight percent of births took place with assistance from a health professional, and 31 percent were delivered by a traditional birth attendant. Only 35 percent of home deliveries were assisted by a health professional. A disposable delivery kit (DDK) was used for seven in ten home birth.

iii. Postnatal care: Early postnatal care for a mother helps safeguard her health and can reduce maternal mortality. The majority of mothers in Punjab (62\%) had a postnatal check-up within two days of birth, as is recommended. More than onethird of women (35\%) received no postnatal care for their last birth in the past five years. Postnatal care is most common following births in a medical facility; however, 11 percent of births in medical facilities were not followed by a postnatal check-up of the mother. Only one-third of home births were followed by a postnatal check-up.

iv. Male involvement in maternal care: Among men with a child under three years, whose mother had at least one antenatal check-up, about 58 percent said they were present during at least one of the antenatal check-ups; and 52 percent were told what to do if the mother had a pregnancy complication. The majority of fathers in Punjab with a child less than three years of age were provided information related to delivery care. Two-thirds were told about the importance of proper nutrition for the mother during pregnancy and 64 percent were told about the importance of delivering the baby in a health facility. Among fathers whose child was not delivered in a health facility, 63 percent were told about the importance of using a new or unused blade to cut the umbilical cord and 67-69 percent each were told about the importance of cleanliness at the time of delivery, the importance of breastfeeding the baby immediately after birth and about keeping the baby warm immediately after birth. About 17 percent Girls age of the age 12-23 months in Punjab are not fully immunized as compared to boys in the same age group and do not received the recommended vaccinations.

v. Sexual behavior: Respondents were asked about their age at first sex, their current and previous sexual partners, and condom use. Additionally, men were asked whether they had paid for sex in the past year. These questions are sensitive and subject to reporting bias, so the results should be interpreted with caution. Half of women age 25-49 first had sex before they were 20 years of age, and half of men in the same age group first had sex before they were 24. Among youth 15-24 years of age, women are more likely than men to have ever had sex ( $37 \%$ of women, compared with $29 \%$ of men). The earlier age at sexual intercourse for women than men is a consequence of the fact that first sexual intercourse largely occurs within marriage and women marry at younger ages than men (IIPS, 2005)

\section{Medical technologies, medicine and Punjab state legislation}

People of Punjab, as appears, are now heading toward the declining sex ratio. One of the main reasons of 'son-mania', as identified by the scholars, is embedded in socio-cultural, economic and political fabric of the State. Further the predominant cause is the agrarian set-up associated with the ownership of land and the social infrastructure sustained by Punjabi's that accords a low status to women. Among the Sikhs in Punjab, a further fall in juvenile sex ratio (780/1000), clearly indicates that social practices among Sikh masses have grossly diverged from the egalitarian principles, emphasizing gender equality, set forth by the "Sikh Guru's" as recorded in the scriptures of "Guru Granth Sahib", the holy book of Sikhs( Singh, Kumar, Vij, 2004).

\subsection{Reproductive technologies and medicine}

Reproductive technologies developed in the late 20th century allow determination of the sex of the unborn child, making "sex selection" through abortion possible in parts of East and South Asia. The "newer" new reproductive technologies, such as prenatal genetic diagnosis and DNA-weighted semen selection, applied for sex selection are easily accessible. The prospects of these new technologies for sex selection must be considered in the light of cultural values surrounding son preference/daughter discrimination in many parts of the world, most notably Asia, as well as preferences for a "gender-balanced" family in much of the West. The ethical issues surrounding these technologies, such as the right to life and the equal treatment of female children, are potentially profound, but legislate appropriate use of these "newest" new reproductive technologies will be difficult.

Sex selective abortions based upon sex determination tests likeamniocentesis, chorionic villous sampling, and ultrasonography have created a win-win situation for all the perpetrators of female feticide. The trauma of repeated conceiving and aborting has been eliminated to a great extent by Newer Reproductive Technologies like pre-conception techniques, pre-implantation genetic diagnosis and DNA probes. With the mobile ultrasound machines moving freely around the countryside, it would just be a matter of time before rural India catches up with its urban counterpart in the race "to do away with the unborn girl child" (Rajalakshmi, 2002).

A case of female foeticide from Fatehgarh Sahib District in Punjab had been reported near $50 \mathrm{~km}$ from Chandigarh. Fatehgarh Sahib has the dubious distinction of being the district with the lowest juvenile sex ratio in the country. The mood is even gloomier today in the house of a family and relative. In March, wife and sister-in-law were arrested by the police on charges of aborting a female foetus[38]. Mothers who had a higher educational status had more gender preferences. Education and higher per capita income has actually empowered couples to access newer technology to practise sex-selective foeticide. In India the use of ultrasound for sex determination started in the late 1970s. It has been estimated that between 1978 and 1983 nearly 78000 female foetuses identified through prenatal sex determination were aborted in India. The authors have used a time-frame of 2 decades to calculate females missing due to prenatal sex determination. The extrapolated figure of 10 million might be on the higher side (Mahlotra, and Kant, 2006).

"Sex determination tests are not conducted here"? Such boards displayed in nursing homes, hospitals are just a ploy to hoodwink the authorities. The reports of recovery of female fetuses from drains, garbage dumps, public lavatories etc. have created shock and public outrage in the state [40]. Legal instruments like maternal termination of pregnancy Act (MTP Act, 1971) and Pre-natal Diagnostic Test Act (PNDT Act)-1994 and its subsequent amendments failed to check this menace. Governmental efforts through ad-campaigns, documentaries, workshops 
etc. have proved inadequate in this regard. In wake of these developments, "Akal Takht", the highest seat of political and spiritual power of Sikhs has raised an alarm. A "Hukumnama" or edict has been issued on 18th April 2001, that any Sikh indulging in female feticide could be excommunicated as the practice was forbidden under "Rehat Maryada"(The Sikh code of religious conduct) issued by Shiromani Gurudwara Prabandhak Committee(SGPC)(ibid).

Under Section 312, whoever voluntarily causes a woman with a child to miscarry, shall, if such miscarriage be not caused in good faith for the purpose of saving the life of the woman, be punished with imprisonment of either description for a term which may extend to three years, or with fine, or with both, and if the woman be quick with child, shall be punished with imprisonment of either description for a term which may extend to seven years, and shall also be liable to pay a fine. A woman who causes her to miscarry also falls within the ambit of this section. The MTP Act, 1971 legalises abortion though it lays down several conditions under which such a procedure may be performed. Section 120 pertains to concealing a design to commit an offence and this is punishable with imprisonment.

Section 312 of the Act hardly had any relevance after the passage of the MTP Act and was rarely invoked. Health official had told her that the department was "catching all those persons who were directly involved in the crime". The import and intent of the PNDT Act was to prevent the misuse of foetal sex determination and instead of focusing on the agency that conducted the test, the health department was focusing on foeticide itself. "When women get targeted, the focus gets blunted," she said. Violations of the PNDT Act involve severe punishment. Section 23(3) lays down that any person who seeks the aid of a genetic counseling centre, a genetic laboratory or a genetic clinic or of a medical geneticist, gynecologist or registered medical practitioner, for applying pre-natal diagnostic techniques on any pregnant woman (unless there is evidence she was compelled to undergo such diagnostic techniques) for purposes other than those specified, shall be punishable with imprisonment for a term that may extend to three years and with a fine which may extend to Rs.10,000 and any subsequent conviction may involve imprisonment which may extend to five years and a fine of up to Rs.50,000. Unless it can be proved that the pregnant woman was compelled by someone to undergo a pre-natal diagnostic test, Section 23(3) will apply to her too. Certain amendments have been proposed to the PNDT Act by the Ministry of Health and Family Welfare including the exclusion of pregnant woman from the punitive provisions of Section 23(3) (Rajalakshmi, 2002).

Action Aids research findings also blames the use of ultrasound technology to determine the sex of the unborn child, for the declining female sex ratio. Though sex selection and selective abortion have been outlawed in India since 1994, poor enforcement ensures that the practice continues. The report says that doctors, nurses and medical practitioners are profiteering from the discrimination against daughters. Many of the 6,000 families interviewed for this research said clinics that carry out sex detection scans and sex selective abortions for a few thousand rupees are wide spread. Some medical professionals interviewed for this research justified sex selective abortions as being a social duty which prevented the ill-treatment of unwanted daughters or helped with population control. The report quotes a doctor as saying that every day families come to her for ultrasound scans and the first question they ask is not about whether their baby is healthy but whether it is a boy or a girl. In poorer areas, with less access to technology, it is neglect that ensures there are fewer surviving daughters, says the report. Child mortality rates in two of the poorer sites researches showed figures significantly skewed against girls (Action Aids, 2008).

Studies in India have indicated three factors of son preference in India, which are the economic utility, sociocultural utility, and religious functions. The factor as to economic utility is that studies indicate that sons are more likely than daughters to provide family farm labor or provide in or for a family business, earn wages, and give old-age support for parents. Upon marriage, a son makes a daughter-in-law an addition and asset to the family providing additional assistance in household work and brings an economic reward through dowry payments, while daughters get married off and merit an economic penalty through dowry charges. The sociocultural utility factor of son preference is that, as in China, in India's patrilineal and patriarchal system of families is that having at least one son is mandatory in order to continue the familial line, and many sons constitute additional status to families. The final factor of son preference is the religious functions that only sons are allowed to provide, based on Hindu tradition. Hindu tradition says that sons are mandatory in order to kindle the funeral pyre of their late parents and to assist in the soul salvation.

Family with strong male bias should be psychologically counseled. So far as sex selection as an offence is concerned, it should be made cognizable and tried under the same section as "Attempt to murder" (Section 307 Indian Penal Code). Also, setting up self-help groups among women, targeting educated women, rewarding all girl families, setting up help-lines adopting new social customs, banning dowry stringently, registering and taking care of expectant mothers including postpartum follow-up, rewarding voluntary sterilization in girl dominating families etc. are some other measures. At weddings, Pandit's /Granthi's /Kazi's etc. should forbid the couple against discrimination to girl child. Television channels like "Sanskar" and "Aastha" can play a positive role in this direction. The edict issued by SGPC in 2001 is a very positive step in curtailing female feticide. The National Commission of Minorities, too, has decided to take up the issue beginning with "Sikh's \& Punjabi's". The 'Jathedars' should also be incorporated in this noble mission. The Central Social Welfare Board has started implementation of "Manvi Sanrakshan Abhiyan" all over the country by 32 state boards. Recently, the Sikh religious leaders and top government officials participated in a "Oath taking" ceremony as a gesture for the commitment to the cause of unborn girl child (Singh, Kumar, Vij, 2004).

An inverse relationship of sex ratio with birth order was documented from Haryana in 2001. This is probably an indication of a more evolved consumer who had more confidence in the technology and used it more rationally Bardia, et al.2004). This study also highlights that the first-order birth itself witnessed sex selection. In a study conducted in Punjab, prenatal sex determination was reported for $9.1 \%$ of infants, especially if the family already had daughters and a high monthly income (Booth, Verma, Beri, 1994). Awareness of ultrasound as a technique for prenatal sex determination is high in the general population. In a communitybased study in Delhi, over $70 \%$ of respondents knew that the sex of a baby can be determined during pregnancy and most of them said it could be done by ultrasound (Chaturvedi, et al. 2001). There is also evidence that sex-selective abortions have increased dramatically in India (Oomman, and Ganatra, 2002).

\subsection{Attitude towards female foeticide}

The State must plan a comprehensive approach that includes alerting media, creating community-based networks to advocate against this practice, sensitizing health providers and involving youth and other stakeholders to curb foeticide. For example, in Haryana, a State where sex ratio imbalance is the highest, women have banded together to form jagriti mandalis ('forums of awakening') aimed at promoting the rights of daughters. To counter the huge profits inherent in providing sex identification services and abortions, these groups are attempting to convince families and doctors of the broader social costs. In Himachel Pradesh, the state government recently revoked laws penalizing elected representatives that choose to have more than two children; while in Punjab; religious leaders have issued diktats and have threatened to excommunicate couples who abort female foetuses. State is striving to control the use of ultrasound and operators now forbidden to divulge the sex of would-be offspring, in many regions. 
Reports have also surfaced of authorities targeting women, who are themselves, victims of discrimination, instead of focusing their attentions on the doctors and technicians who have much to lose from the crack-down on such a lucrative enterprise. In many regions, women who fail to deliver boys are harassed by their inlaws or thrown out on the street. In the interview with Janmanch, an Indian voluntary organization, a former civil surgeon and Haryana State Appropriate Authority for the Pre Natal Determination Technique Act, charges that doctors1, "have forgotten their ethics, and are organized in gangster-like Mafia and are making 2000 Indian rupees per day in commissions for ultrasonographers" (Leidl ,2005).

Walia (2005) analyzed the attitude, reasons and suggestion in her study on female foeticide among the farming and nonfarming population groups of three districts, Ludhiana, Bathinda and Ferozepur of Punjab ( Walia, 2005). In Ludhiana respondents agreed to female foeticide. The reasons were the dowry as the main cause for female foeticide. People of Bathinda admitted about female foeticide and many female respondents openly admitted to have undergone female foeticide. Some respondents used the pretext of preferring a male child to give company to their already present male children. They would lose their respect in the society if they had only daughters. In the total sample from Bathinda region, 18.75 percent of the respondents looked down upon this act. They felt that it was a crime, which should be punished by law. They felt that every living being has to undergo 84 lakhs cycles of birth and death. By killing a living being in the womb, we send the girl child one step backward in the cycle of birth and death. In Bathinda overwhelming majority of respondents said dowry is the main cause. They reported the slogans like "Better to spend Rs. 1000 now and save Rs. 10 lakh later" given by doctors. In Bathinda a majority of 75 percent of those who approved of female foeticide expressed that girls were an unnecessary investment. They repeated, "Bringing up a daughter is like watering a neighbourer's plant". They felt that parents brought up daughters, gave them the best of clothing and facilities only to be taken over by her in laws. Even if a girl was earning, the parents had no right to that earning. It was shared by her in-laws. A considerable 60 percent of the respondents cited post marital problems faced by the girl, lack of social security provided by female children and denial of property to the girl child as the reason for approving female foeticide. They even categorically took the name of the doctor who indulged in eliminating female fetuses (Ibid).

In Ferozepur the respondents have admitted the female foeticide. The respondents with this attitude felt one girl was more than sufficient in a family. They went to the extent of demanding more easy and accessible facilities for sex detection and consequently female foeticide. In Ferozepur very people expressed their dissent towards female foeticide. Here too dowry has emerged as the major reason of female foeticide. Walia (2005) concludes in her study that an overwhelming majority of the respondent's three districts expressed their apphrensions about finding a suitable match for their male children if the sex ratio continued to decline in future. They felt it might lead to a society where there would be "all male families" (Leidl, 2005).

The unholy alliance between tradition (son complex) and technology (ultrasound) is playing havoc with Indian society. The mindless consumerism which is being propagated for 24 hours on TV channels is helping this process. Increasing greed goes with increasing dowry. The message for would be a parent is clear: If you produce girls you will be financially crippled. Better to spend a few thousand rupees now on pre-birth sex determination tests and sex selective abortions rather than spend lakhs of rupees on dowry after years of saving. Who will lament for the unborn daughters? (Walia, 2005).

Walia (2005) recommended some suggestion, we feel agreed, briefly as follows (Walia, 2005).

Legislative measures should be stringently implemented to prevent female foeticide and female infanticide: The doctors and nurses who are found guilty should be punished. They wanted that laws should also be strictly enforced regarding giving and taking of dowry. A considerable 68.75 percent of the sample from Ludhiana wanted that free and compulsory education should be provided to female children so that they could support themselves during exigencies. The non-farming respondents gave lesser impetus to this as compared to the farming respondents as they were mostly poor and did not realize the importance of education in the life of a girl child.

Women should be imparted skills and training through various vocational programmes: if a girl child had some skill she could also augment the income of their poor family. The farming respondents wanted their daughters to stay at home and not to work outside.

Government should start various schemes economically benefited to those families who had daughters. The Punjab Government launched a 'Shagan scheme' and Rs. 5001/- as shagan is given to the parents wherever a female was getting married off by her parents.

Instead of decennial surveys, annual appraisal of sex ratio in worst affected states and districts should be done. Daughters should get the right to perform the last rites of their parents' equivalent to that of sons. The government should amend the existing laws of inheritance. The daughter should be accepted as heir to ancestral property legally as well as socially. Exemplary punishment should be given to the doctors who aid/indulge in this heinous practice of conducting sex determination tests. Such doctors should be punished by Medical Council of India (MCI) under the offence of "Professional Misconduct".

When men and women have near equal chances for survival, there are bound to be near-equal number of males and females in society. In India, however, the female population is much lower than the male population due to higher mortality among females, particularly during their reproductive span. The sex ratio in the Indian population has been falling consistently. From 972 women per 1,000 men in 1901, the sex ratio fell to 933 women per 1,000 men in 2001. This is a cause for concern as it is a telling indicator of the health and social status of women in society, which has a direct and immediate bearing on other key indicators like child mortality. Sex ratio is also calculated for various age groups, the most important being 0-6 years. An adverse sex ratio here shows that fewer girls are being born compared to boys and so indicates discrimination against the female foetus- this could be at the time of conception, gestation or delivery. An adverse 0-6 sex ratio also reveals that socio-cultural factors are determining survival chances of the female (NPSF-3) (IIPS, 2005).

Anthropologically it has been observed that societies with adverse female sex ratio have indicated the presence of customs like polyandry and abduction and purchase of women. It is strongly felt, that contrary to raising the status of women, adverse sex ratio would increase the incidence of rape, prostitution and violence against women (Punjab NewsLine, 2008). The cultural preference for boys, Indian women is put under intense pressure to produce sons. "In the long term, cultural attitudes need to change. This, it says, is because of the "high premium placed on marriage in India, with dowry a major source of pressure for families with daughters. Such practices must be challenged if daughters are to be seen as anything other than an economic burden". Improving the quality of and access to public health systems and government schools must also be a priority, so that poor families do not need to choose which child receives these basic services, the report adds(Action Aids, 2008).

A massive campaign known as "Nawanshahr Model" was started across the country, included the constitution of a federation of district NGOs and its registration under the name "Upkar Coordination Society", holding of meetings at village, block, tehsil and district levels, tracking the pregnancies of expecting mothers, medical audit of scanning centres, adoption of villages by departmental officers and mobilization of youth. The campaign also included some extraordinary measures like mourning of a baby girl in case of abortion preceded by sex determination test. All this resulted in the increase in sex ratio to over 900 in 77 
villages out 475 in the district in a short span (in some villages the ratio had crossed even 1,000 mark). At that time, the national media had attributed the increase in sex ratio in Nawanshahr to the change in people's mindset brought about by aggressive campaigning of Upkar. But that was a fallacy, as it has now turned out. As soon as then District Commissioner was shifted from the district, though the Upkar continued with its awareness campaign, the fear of law created in the minds of the people too evaporated and Nawanshahr district currently occupies a third place from bottom with Gurdaspur and Tarn Taran districts falling behind it with 794 and 736 sex ratios, respectively (Punjab NewLine, 2008).

\section{Anthropology of reproduction}

Before we conclude, the attention may be given to the Reproductive Years, 15-39 years, as we have seen various aspects of this age bracket about the age at marriage, conception, fertility level, abortion and induced abortion, still births, miscarriages etc. This span offers us new vista of analyses to the phenomena of human reproduction: which has been widely studied in two different ways. On one side as Biological process including physiology of the process, including menstruation, coitus, conception, gestation, pregnancy, parturition, infertility, abortion and menopause have been analyzed. These studies concern with the nature of abnormal and normal gestational process(Annis, 1978), psychological correlates of infertility(Edelmann, and Connolly, 1986), spontaneous abortion(La Roche et al. 1984) and studies focused on the teenage pregnancy, repetitive therapeutic abortion(Gibb, 1984) reflecting the biological process of human reproduction and produced the quantum of knowledge of the various aspects of human reproduction(Rapp 1999; Ginsburg and Rapp,1991; Lazarus, 1994; Konard, 2005). Rayna Rapp in her work Testing Women and Testing the Fetus: The social History of Amniocentesis has disclosed herself undergoing such test, as the participant observer and as the feminist anthropologist, for the screening the Down's syndrome and her own pregnancy cut short due to latter. Further Rapp elaborately discussed these reproductive technologies as the socio-cultural process and multiple domains. These technologies were ideally utilized for the welfare of the people. But subsequently these are being (mis)utilized at a large scale to exploit the human emotions and preventing the suffering of the people. Similarly Monica Konard explores in her work about the Anonymity of nameless relation in case of potential Ova donor and recipient (Konard, 2005). Whereas, the other side of human reproduction as Socio-cultural process has been widely studied (Stephen, 1988; Harris and Young, 1981).

Anthropological discourse can reveal further that how the pharmaceutical industries offering Pill Culture for not to reproduce or even not to conceive at all. Several solutions as the option are open to the eligible people or the reproductively active population. Are not these solutions indirectly adding to decline birth and adding to the problem? Or are these solutions not changing the trajectory from infanticides to foeticides and not to reproduce or even not to conceive. Or has "not to conceive" been emerging a way of modern life style? Is it the need of present time? This is very common or not it needs further investigation in the age brackets of 15-39 years. More men and women are delaying their marriage and lessening the chances to have more number of children. Further, it is affected by the sex selection procedures to get a male or deleting unborn girl child from the images. As earlier said most of the women and men want to have one or two son or the one sex of each. Such statistical presentation need to be viewed anthropologically as the constraints in fertility, causing variations in the fertility and the reasons can be explained by five intermediate fertility variables as mentioned above.

\section{Conclusion}

Anthropological implication of missing Girls and their prevailing intervention make us to think about Missing Girls- Is it cultural construction? Or is it statistical representation? If it is a cultural construction which is statistically represented must be examined carefully again particularly in the districts of Punjab where we observed the sex ratio has declined severely and their reason must be seen in its socio-cultural ecology of change controlling the human behavior in reproductively effective years. Solution to tackle this problem must take into consideration basic human existences under unfavorable circumstances. Let see the following plight.

Ranu killed her first two children by strangling those hours after their birth. Both were girls. Married at the age of 18 in the northern, drought-prone Indian state of Rajasthan, Ranu has been pregnant seven times. Two sons died from infections acquired in infancy, two other pregnancies were terminated because the foetuses were female. Ranu is understandably protective of the small boy that today is her only living offspring. Nevertheless she remains defiant. "I will kill other children if they are born girls," she says, adding that she has no money to pay for their weddings. Her husband Muktar, a serviceman, seems unconcerned over the fate of his 'missing' daughters. And why should he be? In districts all over the state, and indeed, all over the country, the elimination of girl children, either through sexselective abortion or infanticide, goes largely uncensured, undetected, unpunished and unmourned. "The girl child is killed by putting a sand bag on her face or by throttling her," explains Ranu, "It is not a rare phenomenon. It happens without any hindrance." [46].

From this narration what do we learn anthropologically? We have seen the female infanticide historically had been widely practiced throughout the world for the centuries in different cultures. Despite all efforts it is yet still continues! What does it indicate? What is the mindset of the People about the girls and factors regulating their mind? What kind of thoughts rule, cultural construction, the mind of the people? These words "I will kill other children if they are born girls," she says, adding that she has no money to pay for their weddings, this reflects the images of the girl child this mother has, and same is ruling their mind. How these images of the Girl child are inherited and continue to sustain and finally shaped in to the attributes of Culture of the Missing girls? Does it mean people of the Punjab districts with low sex ratio facing, similarly, invisible terror of the Girls- are they images of expenditure? Or are they for "Seedlings of other families"? Or are they victim of abuses? These culturally constructed images of the Girl child are being forced in the mind of the people of country including Punjab or these seem to be responsible for the enhancing the trajectory of female infanticide to foeticide. Clearly, mother who herself suffered in the same way now she does not want her daughter to be suffered in the same way in future. The continuances of the images of the Girl child among growing girls, future the mothers or fathers force to adopt these easy means and ways. These means were earlier an easy trajectory of female infanticide, then abortion, now more easily to foeticide then finally pills culture offered a solution to the saliently invisible sufferings of the reproductive years of men and women affected the entire natural course of reproduction.

Most of us may view as several authors have blamed the reproductive technologies as hazardous and have created more catastrophic results in the sex ratio decline. Their interpretation heavily drawn on one side, negative sides, of this advancement, but these reproductive techniques initially were used for the human welfare: to diagnose malformations, genetic defects, or we can say for the healthy production of the baby. Gradually shift has taken place in its (mis)use which fueled by the culturally constructed images of the Son or Daughter. Here we feel there is 
urgent need to change these culturally constructed images in mindset of people in the Punjab.

The law and police, policies, MCI of the State, educational institutions etc. all are taking its course, but still it prevails! We should strive for the solution, though we do not find it easy; solution to this growing problem lies in the holistic manner aiming to self-moralization of the people wherever they exist or like to exist.

In the last, the religious texts of Hindu, Sikh, and Muslim as were used to prevent infanticide; though failed; in preindependent India (Vishwanath, 1998) may be offered again from the teaching of the great saint and divine revelation of Guru Nanak who preached to all his followers: "From woman, man is born; within woman man is conceived; to woman he is engaged and married; women becomes his friend; when his women dies, he seeks another woman; to woman he is bound. So why call her bad? From her kings are born". Such images of the Girl: unborn or born we need to impose in mind of the men and women. India's missing women cannot be brought back to life but the future generations of women and men of Punjab must plan their life as the latter Saint Guru Nanak remind the whole humanity.

\section{Acknowledgement}

We are thankful to Prof D C Jain, Professor of Neurology and former Director, IHBAS, Delhi and former Director-General of Health Services, Govt. of India for permitting first author to present this invited paper in National Seminar on Population and Development: Issues and Challenges in Punjab, March, 3-5, 2009, Chandigarh, India. Besides we also express our gratitude to Dr. F Ram, Director, IIPS, Mumbai for his valuable comments and suggestions its earlier drafts.

\section{References}

[1] Action Aids (2008). Alarming decline in female sex ratio, June 2008 Anand, M. (2004). Female Foeticide - A quest for survival. Social Welfare. Sept. 5-8.

[2] Annis, Linda Ferrill (1978). The Child before Birth. Ithaca: Cornell University Press Bardia A, Paul E, Kapoor S.K, Anand, K. (2004). Decline sex ratios: Role of society, Technology and government regulation in Faridabad district, Haryana. NatlMed J India; 17:207-11.

[3] Basu, A.M. (1989). Is discrimination in food really necessary for explaining sex differentials in childhood mortality? Population Studies; 43:193-200.

[4] Bastian M L. (2001). The demon superstition: abominable twins and mission culture in Onitsha history. Ethnology 40:13-27.

[5] Becker, G. (2000). On the Bones of the Serpent: Person, Memory, and Mortality in Sabarl Island gies. Berkeley: Univ. Calif. Press. 320 pp.

[6] Browner C, Sargent CF. (1996). Anthropological studies of human reproduction. In Medical Anthropology: Contemporary Theory and Method, ed. CF Sargent, TM Johnson, pp. 218-35. Westport, CT: Praeger

[7] Booth, BE, Verma M, Beri RS (1994). Fetal sex determination in infants in Punjab,India: Correlations and implications. $B M J$; 309:1259-61.

[8] Cecil R. (1996). The Anthropology of Pregnancy Loss: Comparative Studies in Miscarriage, Stillbirth, and Neonatal Death. Oxford, UK/Washington, DC: Berg. $226 \mathrm{pp}$

[9] Chaturvedi S, Aggarwal OP, Bhasin SK, Gupta P (2001). Prenatal sex determination: a community-based investigation in East Delhi. Trop Doct; 31:204-6.

[10]Csordas TJ. (1996). a handmaid's tale: the rhetoric of personhood in American and Japanese healing of abortions. In Gender and Health: An International Perspective, ed. CF Sargent, C Brettell, pp. 227-41. Upper Saddle River, NJ: Prentice Hall.

[11]Davis-Floyd R, Dumit J, eds. (1997). Introduction: the anthropology of birth. In childbirth and Authoriative knowledge: Cross-Cultural Perspectives, ed. R Davis-Floyd, CF Sargent, pp. 1-51. Berkeley: Univ. Calif. Press.

[12]Dube L (1983). Misadventures in amniocentesis. Economic and Political Weekly 40 (2): 279-80.
[13]Edelmann, RJ. And Connolly, KJ. (1986) Psychological aspects of infertility. Br. J. Med. Psychol., 59, 209-219.

[14]Gibb,G.D. (1984). A comparative Study of Recidivist and contraceptorsal and the dimensions of control Impulsivity. International Journal of Psychiatry19(6):581-91

[15]Ginsburg, Faye and Rayna Rapp (1991). The Politics of Reproduction. Annual review of Anthropology.20:311-343

[16]Greenhalghs.(2003). Unplanned persons and gendered children planned births, unplanned persons: "population" in the making of Chinese modernity. Am. Ethol. 30:196-215

[17]Hartouni V. (1997). Cultural Conceptions: On Reproductive Technologies and the Remaking of Life. Minneapolis: Univ. Minn. Press. $175 \mathrm{pp}$.

[18]Handwerker, W. Penn (1990). Demography. In Medical Anthropology-A hand book of Theory and Practices. Edited by T M Jhonson and C F Sargent. Green Wood Press

[19]Hardacre H. (1997). Marketing the Menacing Fetus in Japan. Berkeley: Univ. Calif. Press.

[20]Harris Olivia and Kate Young (1981). Engendered structures: Some problems in the Analysis of Reproduction. In Anthropology Pre-capitalistic Societies. Joel Khan and Loblra Joseph eds. London.

[21]Inhorn MC, Van Balen F, eds. (2002). Infertility Around the Globe: New Thinking on Childlessness, gender, and Reproductive Technologies. Berkeley: Univ. Calif. Press. 347 pp.

[22]IIPS (2005). National Family Health Survey (NFHS-3) Vol.-I, International Institute of Population sciences (IIPS), India, 2005-06: Mumbai: .Konard, Monica (2005). Nameless Relations: Anonymity, Melanesia and Reproductive Gift Exchange between British ova Donors and Recipients. Berghan Books. New York and Oxford

[23]Kahn S M. (2000). Reproducing Jews: A Cultural Account of Assisted Conception in Israel. Durhan: Duke Univ. Press. 227 pp.

[24]Krishna Kumari DB, Vani C. (2004). Media for Gender Empowerment. Social Welfare. Oct.; 37-40.

[25]Landsman GH. (1998). Reconstructing motherland in the age of "perfect" babies: mothers of infants and toddlers with disabilities. Signs 24:169-99.

[26]Layne LL. (2003). Motherhood Lost: A Feminist Account of pregnancy Loss in America. New York: Routledge. 354 pp.

[27]La Roche et al. (1984). Grief Reactions to Prenatal death. A followup study. Canadian Journal of Psychiatry.29(1):14-19

[28]Lazarus, Ellen S. (1994) what do women want? Issues of Choice, Control, and Class in Pregnancy and Child Birth. Medical Anthropology Quarterly 8(1)25-46

[29]Mahlotra, Sumit and Kant,S.(2006). Adverse Female to male Sex ratio at birth in India: A Cause for concerns. Comment. The National Medical Journal of Inida. vol 19,3,,2006 p 151-2.

[30]Mallick A. (2004).India's Missing Women. Social Welfare. July; 410.

[31]Miller BD.(1989) Son preference, the household and a public health program in north

[32] India. In: Maithreyi K, Karuna C (eds). Women and the household in Asia. New York:Sage Publications; 1989:191-208.

[33] Miller BD (1985). Prenatal and postnatal sex-selection in India: The patriarchal Context, ethical questions and public policy. Working paper 107, Women in International Development Publication Series. Michigan State University,MI 1985

[34]Miller BD. (2001). Female-selective abortion in Asia: patterns, policies, and debates. Am. Anthropol. 103:1083-95.

[35] Morgan LM. (2002). "Properly disposed of": a history of embryo disposal and the changing claims on fetal remains. Med. Anthropol. 21:247-74.

[36]Oaks L. (1994). Fetal spirihood and fetal personhood - the cultural construction of abortion in Japan. Women's Studding Int. Q. 17:51123.

[37] Oomman N, Ganatra BR (2002). Sex selection: The systematic elimination of girls. Reprod Health Matters; 10:184-8.

[38]Punjab New Line (2008). Sorry, sex ratio dips again in Nawanshehar, 3 July.

[39]Parson H. (2004). Making Modern Mothers: Ethics and Family Planning in Urban Greece. Berkeley: Univ. Calif. Press. 335 pp.

[40]Patricia Leidl (2005). The State of World Population 2005. The Promise of Equality: Gender Equity, Reproductive Health and the Millennium Development Goals. Silent spring: The tragedy of India's never-born girls.

[41]Picone M. (1998). Infanticide, the spirits of aborted fetuses, and the making of motherhood in Japan. See Scheper-Hughes \& Sargent pp. 37-57.

[42]Rajalakshmi, T.K. (2002). Female foeticide in Punjab. Frontline. Vol.19.12, June 8-21, Rapp R. (1999). Testing Women, Testing the 
Fetus: The Social Impact of Amniocentesis in America. New York: Routledge. $361 \mathrm{pp}$.

[43]Rastogi SR and Kumari R. (1992). Son preference and effectiveness of the family welfare programme in Uttar Pradesh. In: Patil RN (ed). Health, environment and Population. New Delhi:Ashish Publishing; :165-79.

[44]Singh D, Kumar A, Vij K,(2004) Skewed Sex ratio in Punjab- A Demographic catastrophe. IIJFMT 2(4).

[45]Stephen,Lynn (1988). Zapotec gender Politics: the creation of Political arena by and for peasant women. A Paper presented in AAA, Phoneix.

[46]Trussell, T James (1979). Natural fertility: Measurement and Use in Fertility models. In Natural fertility by Henri L. and Jane Menken (Edited).

[47]Visaria L. (2002) Deficit of women in India: Magnitude, trends, regional variations and determinants. Natl Med J India; 15 (Suppl 1):19-25.

[48] Van Hollen CC. (1994). Perspectives on the Anthropology of birth: a review. Cult. Med. Psychiatry 18:501-12.

[49]Van Hollen CC. (2003). Birth on the Threshold: Childbirth and Modernity in South India. Berkeley: Univ. Calif. Press. 295 pp.

[50]Vishwanath, L S (1998). Efforts of Colonial State to Suppress Female Infanticide: Use of Sacred Texts, Generation of Knowledge. Economic and Political Weekly. 33(19) May 9, P.1104-1112.

[51] Walia, Ajinder (2005). Female Foeticide in Punjab: Exploring the socio-economic and cultural dimensions. IDEA, A journal of Social Issues, August 9, 2005 -- Vol.10, No.1.

[52]Williamson, Laila (1998). Hardness of Heart and Hardness of Life: A Brief History of Infanticide General Historical Evidence. The Society for the Prevention of Infanticide,Amzone, USA.

[53]Wood, James W. and Maxine, Weinstein (1988). A model of Age Specific Fecundability. Population Studies. 42:85-114. 